\title{
Patrimônio cultural, turismo e ordenamento territorial
}

\section{Cultural heritage, tourism and territorial planning}

\author{
Nabila Suelly Souza Pereira (PEREIRA, N. S. S.) ${ }^{*}$
}

\begin{abstract}
RESUMO - Este artigo trata-se de uma abordagem teórica da relação entre patrimônio cultural, atividades turísticas e sua influência sobre o ordenamento territorial no espaço, mais precisamente o espaço urbano. O conteúdo aqui problematizado é resultado de pesquisas e discussões realizadas no âmbito do patrimônio cultural e geografia. A pesquisa foi realizada no ano de 2016 e a metodologia utilizada foi levantamento bibliográfico acerca da categoria Patrimônio Cultural, geografia urbana e turismo relacionado com ordenamento territorial. O ensaio demonstra como possível resultado a influência que o patrimônio revelado como um atrativo turístico mostra-se um importante eixo para as questões de ordenamento territorial. E o campo conflituoso e contraditório que permeia o patrimônio, no âmbito do ordenamento territorial para atividade turística, muitas vezes proporciona conflitos entre territorialidades antigas e territorialidades novas quando estão estritamente a serviço do mercado.
\end{abstract}

Palavras-chave: Turismo; Patrimônio; Ordenamento territorial; Urbano.

ABSTRACT - This article discusses a theoretical approach of the relationship between cultural heritage, tourist activities and their influence on the territorial planning in space, more precisely the urban space. The content here is the result of research and discussions on cultural heritage and geography. The research was carried out in the year of 2016 and the methodology used was a bibliographic research about the category Cultural heritage, Urban Geography and Tourism related to territorial planning. The essay demonstrates, as possible result, the influence that the cultural heritage revealed as a tourist attraction is an important axis for the territorial planning issues. And the conflicting and contradictory field that permeates the "cultural heritage" issue, in the context of territorial planning for tourism, often leads to conflicts between old territorialities and new territorialities when they are strictly at the service of the real estate market.

Key words: Tourism; Heritage; Territorial planning; Urban.

\footnotetext{
* Formação: Graduação em Geografia pela Universidade Federal do Pará (UFPA), Especialização em Gestão e Planejamento do Patrimônio Cultural pelo Núcleo de Altos Estudos Amazônicos - NAEA, Mestranda em Geografia pelo Programa de Pós-Graduação em Geografia - PPGEO (UFPA). Atividade profissional: Agente de pesquisa e mapeamento no Instituto Brasileiro de Geografia e Estatística - IBGE. Endereço físico para correspondência: Av. Independência, passagem São Pedro, bairro Cabanagem. CEP: 66625-500 - Belém - Pará - Brasil. E-mail: nabilapereira@ hotmail.com
} 


\section{INTRODUÇÃO}

Este artigo trata-se da discussão da categoria patrimônio cultural, turismo e o ordenamento territorial, dando alguns apontamentos sobre o conceito de patrimônio em construção e apresentando um breve histórico da evolução da patrimonialização no Brasil e no Mundo. A metodologia utilizada foi revisão bibliográfica acerca da categoria patrimônio, sua relação com o turismo cultural, a perspectiva mercadológica sobre o consumo de espaços patrimonializados e a relação com ordenamento territorial. Nessa perspectiva, apresentam-se os desdobramentos propostos para o conceito de patrimônio demonstrando o vasto campo de atuação que essa discussão pode alcançar.

Os autores apresentados no texto tratam da temática do Patrimônio relacionando-o com a produção do espaço e o ordenamento territorial. Tais como: Jeudy (2005), Cruz (2012), Paes (2006, 2009, 2010), Nigro (2005, 2010), Cifelli (2010) e Costa (2015), auxiliando na perspectiva de discussão sobre Patrimônio, Patrimonialização e turismo.

O patrimônio sendo uma categoria que permite uma análise no âmbito cultural, econômico, natural e político pode subsidiar diversas questões para a compreensão do espaço, das contradições do consumo do turismo cultural e do ordenamento territorial. Nesse sentido que se busca neste texto contribuir para a discussão das antigas e atuais funcionalidades de patrimonialização e suas repercussões no espaço. Tratando da valorização de centros urbanos antigos, dos processos de intervenção urbana como refuncionalização, a contradição do uso do espaço no bojo da mercantilização e espetacularização das cidades.

\section{A CATEGORIA PATRIMÔNIO}

Para Choay (2001), a palavra patrimônio, na sua origem, estava ligada às estruturas familiares, econômicas e jurídicas de uma sociedade enraizada no espaço e no tempo. É um conceito que vem sendo cada vez mais discutido, e tal discussão faz do patrimônio um importante eixo para obtenção de ações de preservação dos bens representativos, como bens históricos, artísticos, culturais e ambientais. Alguns autores 
afirmam que o patrimônio teve sua noção fortalecida no século XIX, sob o ideário iluminista, uma vez que o significado de nação estava intimamente atrelado à posse de um território e de uma cultura (NIGRO, 2005). Nesse sentido pode-se afirmar que o uso do conceito de patrimônio histórico e artístico fora uma arma de estratégia para assegurar a posse pública de bens culturais, de modo que legitima uma cultura, em nome de uma coletividade, e o mesmo passa a ser usado como uma espécie de documento da história oficial.

A categoria patrimônio está imbricada em um campo conflituoso e complexo, pois "quando o espaço transpõe o tempo na memória social ele torna-se patrimônio, campo conflituoso de representações sócio-políticas" (FIGUEREDO, 2013, p. 56). As questões patrimoniais a partir do século $\mathrm{XX}$ adquiriram um papel bastante relevante nas relações sociais, culturais e econômicas no mundo. De acordo com Gonçalveis (2005), se atenta para a omissão feita à categoria patrimônio, afirmando o destaque que esta adquiriu na formação dos estados-nação, no mais, por tratar-se de uma categoria do pensamento, não teve a devida atenção a sua existência para além da invenção moderna, presente em outros tempos, mas com atributo semântico diferenciado da que passou a possuir.

É indiscutível que a categoria patrimônio tenha estabelecido maior visibilidade a partir da criação dos estados-nação, no entanto comumente não se é explanado seu caráter milenar, pois se trata de uma categoria de pensamento, que se faz presente mesmo nas chamadas "culturas primitivas" (GONÇALVES, 2005).

Conforme (NIGRO, 2005), o patrimônio tendo uma visibilidade mais contundente no bojo dos ideários iluministas, herda uma posição extremamente elitista e seu modelo de intervenção nas questões de conservação e preservação dos bens representativos tem caráter pouco ou nada democrático, em que é delegado somente aos técnicos a eleição dos bens a serem preservados e suas ações de intervenção. No entanto as características elitistas sobre o patrimônio passaram a ser questionadas, ganhando maior força no discurso nas décadas de 60 e 70, dando espaço para a chamada “democratização do patrimônio" (NIGRO, 2005). De acordo com essa autora, tal democratização surgiu para discutir o distanciamento das instituições de preservação e sociedade, na tentativa de envolver a população nas decisões promulgadas pelas 
instituições públicas preservacionistas, e quais bens culturais estariam sendo selecionados para representar o patrimônio. (Ver quadro 1).

\begin{tabular}{|c|c|}
\hline \multicolumn{2}{|c|}{ A Democratização do Patrimônio: eventos e seus aspectos e conjuntura. } \\
\hline Evento & Conjuntura/Aspecto \\
\hline \multirow{2}{*}{$\begin{array}{l}\text { A diminuição do } \\
\text { distanciamento entre as } \\
\text { instituições de preservação } \\
\text { e população. }\end{array}$} & $\begin{array}{l}\text { Primeiro momento: corresponde a não participação direta e efetiva da } \\
\text { população nas decisões promulgadas pelas instituições públicas } \\
\text { preservacionistas. }\end{array}$ \\
\hline & $\begin{array}{l}\text { Segundo momento: sobre o questionamento de quais bens culturais estão } \\
\text { sendo selecionados pelas instituições públicas preservacionistas para } \\
\text { representar o patrimônio da sociedade. }\end{array}$ \\
\hline \multirow{3}{*}{$\begin{array}{l}\text { - Ampliação progressiva } \\
\text { do que se considera } \\
\text { patrimônio. }\end{array}$} & $\begin{array}{l}\text { Tipológica: Bens ligados à etnologia rural e urbana, práticas culturais, de } \\
\text { lazer, arquitetura menor ou popular e a arquitetura industrial passam a ser } \\
\text { consideradas também como bens patrimoniais. }\end{array}$ \\
\hline & $\begin{array}{l}\text { Cronológica: Rompe com a ideia de só considerar patrimônio o que é de } \\
\text { passado bastante remoto, incluindo bens correspondentes também da } \\
\text { contemporaneidade. }\end{array}$ \\
\hline & $\begin{array}{l}\text { Geográfica: A patrimonialização não contempla apenas edifícios isolados, } \\
\text { mas conjuntos edificados, bairros, vilarejos, cidades, sítios arqueológicos } \\
\text { e naturais. }\end{array}$ \\
\hline \multirow{4}{*}{$\begin{array}{l}\text { - Ampliação do público do } \\
\text { patrimônio: }\end{array}$} & $\begin{array}{l}\text { Memória social: } \mathrm{O} \text { estreitamento do vínculo entre memória social e } \\
\text { patrimônio impulsiona a articulação de movimentos sociais em defesa da } \\
\text { preservação do patrimônio. Juntamente com o direito à memória, o direito } \\
\text { ao patrimônio enseja que bens materiais investidos de função mnemônica } \\
\text { sejam efetivamente protegidos. (p. 10109). }\end{array}$ \\
\hline & $\begin{array}{l}\text { Natureza: A aproximação do campo do patrimônio com o movimento } \\
\text { ecológico e ao entendimento da natureza como um patrimônio comum, } \\
\text { sobretudo na década de } 70 \text { em que o discurso em defesa do meio ambiente } \\
\text { está mais intenso. }\end{array}$ \\
\hline & $\begin{array}{l}\text { Patrimônio Comum da Humanidade: após a criação desse título pela } \\
\text { UNESCO, supõe a valorização de certos bens culturais e naturais } \\
\text { pertencentes a toda humanidade. Os bens são vistos como heranças } \\
\text { transmissíveis entre gerações, por intermédio das quais somente o coletivo } \\
\text { se tornaria seu proprietário, consolidando, assim, uma riqueza } \\
\text { juridicamente comum. }\end{array}$ \\
\hline & $\begin{array}{l}\text { Turismo cultural: a exploração turística do patrimônio adquire forte } \\
\text { influência nas questões de salvaguarda, viabilizando intervenções de } \\
\text { conservação de bens. Nessa conjuntura se forma a conciliação do } \\
\text { mercado e políticas de preservação. }\end{array}$ \\
\hline
\end{tabular}

No quadro acima se discute sobre como se deram as ações da chamada democratização do patrimônio e a conjuntura na qual estava inserida. O processo de democratização do patrimônio iniciou-se pela diminuição do distanciamento entre as instituições de preservação e a população, onde tais acontecimentos acarretaram na amplitude da ideia do que poderia ser considerado um bem representativo e, por 
conseguinte a ampliação do público envolvido nas questões de eleição, preservação e consumo do patrimônio cultural.

No Brasil, a discussão sobre patrimônio entre as políticas de proteção ganham substancialmente maior visibilidade a partir da década de 20, no bojo do movimento Modernista $^{1}$ (FONSECA, 2009). O movimento modernista desde sua formação claramente constituiu-se num movimento heterogêneo, no entanto o caráter de formação e fortificação de uma identidade nacional apresentava-se como um ponto comum entre os participantes do movimento (FONSECA, 2009).

Ainda de acordo com Fonseca (2009), os intelectuais modernistas adentraram no âmbito da política nacional a partir da década de 30, em que o projeto do Estado Novo era construir uma identidade nacional. Nesse sentido, fazer a proteção e a valorização de monumentos que representassem a nacionalidade brasileira a partir da visão do Estado, atribuía à categoria Patrimônio uma importante missão de caráter ideológico.

Para além de um pensamento estritamente formador de identidades e sim, confirmador destas, Bertoncello (2010) afirma que Patrimônio é algo que se herda, uma transferência de gerações, onde sua condição estaria definida no passado, e sua função no presente seria garantir a preservação e a disposição dos bens patrimoniais a todos. E para Gonçalves (2005) os bens a serem herdados, em muitos casos servem a propósitos práticos e possuem ao mesmo tempo significados mágico-religiosos e sociais, constituindo-se em verdadeiras entidades dotadas de espírito, personalidade e vontade, pois:

\begin{abstract}
Não são desse modo meros objetos. Se por um lado são classificados como partes inseparáveis de totalidades cósmicas e sociais, por outro lado afirmamse como extensões morais e simbólicas de seus proprietários, são extensões destes, sejam indivíduos ou coletividades, estabelecendo mediações cruciais entre eles e o universo cósmico, natural e social. (GONÇALVES, 2005, p. 6).
\end{abstract}

Diante de tais características, para os discursos contemporâneos, fora preciso criar a categoria de patrimônio imaterial e intangível, de forma que o patrimônio abarcasse para além da sua definição convencional de monumentos, prédios, espaços urbanos, objetos.

\footnotetext{
1 "Em termos gerais, o modernismo, nas segunda e terceira décadas do século XX, se propunha como uma revolução artística: mas, sob o lema da critica ao passadismo e à linguagem acadêmica, esse movimento teve diversas orientações estéticas e também ideológicas" (FONSECA, 2009, p. 83).
} 
Patrimônio natural também é um conceito que se configura em um desdobramento de patrimônio cultural, portanto todo patrimônio natural é essencialmente um patrimônio cultural. Scifoni (2010) discute uma nova perspectiva para o entendimento da natureza, no que diz respeito ao patrimônio natural, pois este possibilita compreendê-la como parte da vida humana, uma natureza tornada social. A evolução do conceito supera a ideia de apenas as edificações constituírem-se em patrimônio, valorizando assim, outros objetos, mesmo aqueles que expressam outras culturas, dos mais diversos grupos sociais.

O patrimônio cultural segundo Nigro (2010), nos últimos anos vem ganhando uma intensa visibilidade, uma disseminação de consciência patrimonial, talvez uma tentativa de reafirmação do passado, por isso o tema ganha grande visibilidade desde trabalhos acadêmicos a discurso políticos. Segundo Cruz (2012) não há patrimônio que não seja cultural, seja ele material ou imaterial, uma vez que a cultura é uma condição de produção e reprodução da sociedade (CRUZ, 2012).

Sabendo que nenhum evento se constitui fora do espaço, a questão espacial sob a ótica do patrimônio permite revelar o "campo de tensões sociais e assim revelar como o passado é lembrado e representado e as implicações que isso tem no presente e na construção das relações de 'pertencimento"” (NIGRO, 2010, p. 69). Para Paes (2009), o patrimônio cultural está para além de apenas expressão da sociedade, o patrimônio cultural:

[...] movimenta, aviva, põe em evidência as passagens, as vias de acesso entre o material e o simbólico, entre o sujeito e o seu meio, entre uma razão prática e uma razão simbólica. O patrimônio cultural torna-se um fato social (PAES, 2009, p. 163).

Na perspectiva de diversas discussões a respeito do patrimônio cultural pode-se destacar a que lhe emprega como forma de mercadoria, e por meio de apropriações acaba expressando o interesse de alguns setores públicos e até mesmo privados, podendo ou não acarretar em processos de segregação sócio-espacial, nos quais em grande medida podem-se identificar ocorrências em inúmeras áreas centrais urbanas.

Paes-Luchiari (2006) afirma que a reincorporação dos centros históricos urbanos à economia política das grandes cidades às lógicas da economia global, faz do patrimônio cultural um atrativo, onde as singularidades dos locais passam a ter um valor particular para a esfera turística. 
O consumo do patrimônio cultural estabelece como tais espaços são usados e apropriados, tanto por moradores locais quanto pela esfera pública no âmbito do planejamento urbano. Os projetos de renovação urbana denominados por revitalização, gentrificação $^{2}$, requalificação, refuncionalização ${ }^{3}$ e enobrecimento são formas de intervenções urbanas produtoras, em alguns casos, de segregação espacial, fazem de espaços antes deteriorados e abandonados, espaços disputados por atividades nobres do comércio (PAES-LUCHIARI, 2006). A valorização de bens patrimoniais implica na conservação e preservação destes por parte dos órgãos públicos, e sua dimensão funcional pode sofrer constantes variações, adaptações às finalidades do presente, principalmente aos interesses de cunho mercantil decorrentes de sua valorização política (CIFELLI, 2010). É nessa perspectiva que se torna interessante, quiçá inevitável, tratar da categoria patrimônio relacionando-o com a apropriação do espaço, em todos os casos, para além da apropriação, a produção deste no âmbito do ordenamento territorial.

\section{PATRIMÔNIO CULTURAL, TURISMO E ORDENAMENTO TERRITORIAL}

De acordo com Nigro (2010, p. 75): “Na geografia brasileira, análise do patrimônio tem procurado desvendar conflitos entre os diferentes agentes produtores do espaço, sobretudo nos estudos da Geografia do Turismo e Urbana”. É nesse sentido que a geografia busca trabalhar o patrimônio cultural como um importante elemento para as intervenções urbanas nas áreas centrais.

A utilização da geografia para a análise do patrimônio cultural desenvolvida por Cifelli (2010) utiliza o referencial analítico que estrutura o método geográfico ${ }^{4}$, proposto por Santos (2009), para subsidiar a compreensão evolutiva das formas

\footnotetext{
${ }^{2}$ De acordo com Bernhardt (2005), a gentrificação pode ser considerada como um tipo de revitalização, mas um tipo específico com suas próprias lógicas mercadológicas e de lucratividade. É uma espécie de emburguesamento de bairros que já possuem suas próprias características, tradições e práticas culturais. Um fator fundamental para entender a gentrificação é que sempre implica num deslocamento da população original.

${ }^{3}$ Segundo Paes-Luchiari (2006), refuncionalização designa qualquer intervenção urbana que visa à renovação das formas urbanas herdadas do passado.

${ }^{4}$ O método geográfico exposto por Santos (2009), utilizando as Formas como o aspecto visível de uma coisa; Função sendo a atividade esperada de uma forma; Estrutura sendo o modo de organização ou construção e o Processo como uma ação contínua desenvolvendo-se em direção a um resultado qualquer, implicando conceitos de tempo e mudanças.
} 
espaciais, apoiada na sua relação dialética com função, e atrelada à variação da estrutura social ao longo do processo histórico. Ou seja, entendendo a função das formas no bojo de uma estrutura social estabelecida, se pode compreender o processo histórico. E admitindo as formas patrimoniais, como materialização do tempo no espaço, suas funções podem ou não obter diversas mutações de acordo com a estrutura social em que se encontram no presente. Esta variação das funções condicionam os valores atribuídos às formas, os valores de uso, econômico, estético, e sentimental, os quais variam subordinados às necessidades individuais e coletivas (CIFELLI, 2010).

A disseminação da preservação da memória, por meio da patrimonialização, segundo Paes (2010), remete a questões importantes sobre a organização da sociedade no presente, sobre a atual valorização das coisas, das paisagens e das heranças históricas substanciadas no espaço. Cruz (2012) discute a "patrimonialização do patrimônio", em que esta, mais intensamente empregada no Brasil no início do século $\mathrm{XX}$, propõe a institucionalização de mecanismos de proteção do chamado patrimônio cultural, desenvolvida a partir da afirmação de um reconhecimento de identidade nacional, e com um suposto receio coletivo de assistir à substituição de um dado patrimônio por outro.

Essa maior atenção à categoria é resultado das grandes transformações que ocorreram na sociedade a partir do século XX. Jeudy (2005) discute o advento de uma espécie de "dever de memória" que se lançou na estrutura social ocasionando um processo intenso de culto ao patrimônio e ao reconhecimento de uma memória coletiva que é proibida de ser esquecida. Nessa via, este autor afirma que:

\begin{abstract}
Para além de seu objeto, trata-se, pois, do princípio da transmissão em si, transmitido como um ato e um dever coletivo que ninguém tem o direito de contestar. Este formalismo da transmissão acentuou-se a ponto de tornar puramente maquinal o ato de transmitir, concedendo-lhe um valor simbólico enunciável, que pode ser gerado e indefinidamente reproduzível (JEUDY, 2005, p. 17).
\end{abstract}

Ainda de acordo com Jeudy (2005), os processos de patrimonialização já estão consolidados, agora o que restariam seriam os processos de salvaguarda do que foi "protegido". A cada tempo histórico, os bens representativos vão ganhando novos usos e funcionalidades, haja vista que a produção e reprodução do espaço urbano vão adquirindo novas nuancem com o passar do tempo. Assim a preservação patrimonial também vai assumindo novas funcionalidades e o que antes designava referenciais de 
uma construção de nacionalidade, hoje cada vez mais se encontram envoltos a novos "estímulos da cidadania, de territorialização e reterritorialização de grupos, e somam-se, ainda, a intervenção dos interesses do mercado" (SERRANO, 2007, p. 10).

Nessa via, pode-se discutir a respeito das apropriações do patrimônio cultural, uma vez que as intervenções urbanas não se dão de forma homogênea, abrangem apenas áreas de maior atratividade turística, paisagens, o que pode ser rentável para os investidores do local e global, ou até mesmo "mudam-se as funções dos lugares para transformá-los em espaços museológicos, muitas vezes investindo-se recursos públicos vultosos e retirando, além da função, a vida cidadã existente nesses espaços" (MENESES, 2012, p. 32).

A análise geográfica estabelecida por Cifelli (2010), para compreender a atual importância do patrimônio cultural na organização sócio espacial, apresenta uma intensa renovação urbana apoiada no discurso patrimonialista. E com o discurso de preservação e resgate de um patrimônio que pode estar na esfera tanto material como imaterial. Observa-se em grande evidência a disseminação de valorização destes tipos de áreas. Ainda segundo esta autora, cidades como Parati, no Rio de Janeiro, as cidades históricas de Minas Gerais, receberam uma forma de valorização de espaços que de alguma maneira possuem uma referência simbólica para uma cidade, uma vez que:

\footnotetext{
Tais referências simbólicas se manifestam na paisagem de diversas maneiras, mas, em geral, estão ligadas a formas arquitetônicas ou aos traçados urbanos que se associam às origens e aos antepassados da cidade, como igrejas, ruas, praças, prédios públicos etc., tornando os mesmos em espaços estratégicos, seja do ponto de vista de sua funcionalidade, seja do ponto de vista de seus referenciais simbólicos. (TRINDADE JR, 2008, p. 15937).
}

Essa valorização está relacionada ao apelo turístico que os espaços de memória carregam. A relação do patrimônio com o turismo proporciona cada vez mais uma nova organização do espaço. O consumo turístico dos espaços patrimonializados demonstra uma nova perspectiva de apropriação das cidades. Por sua vez, a atividade turística ao passar dos anos vem apresentando mudanças. De acordo com Bertoncello (2010), a atividade vem recebendo novas modalidades, com atrativos diferenciados e se distanciando, às vezes, das características do turismo de massa. O turismo cultural seria um exemplo dessa nova forma de fazer turismo que tem em grande medida, o patrimônio como principal atrativo. 
No lugar de uma paisagem deteriorada, em alguns casos abandonada, nasce um centro histórico "revitalizado". Segundo Paes-Luchiari (2006), o termo revitalização é muito criticado por pressupor que antes da intervenção da renovação urbana, não havia vida nessas áreas, o que contrasta aos centros ocupados por classes populares. Nessas áreas o que ocorre é uma requalificação, onde os espaços passam a projetar conteúdos sociais e culturais locais, de forma que esses espaços tornam-se atrativos turísticos para as cidades (TRINDADE JR, 2008). ${ }^{5}$

Assim as cidades ganham novos usos apoiadas, em grande medida, sob a forma de um Planejamento estratégico ${ }^{6}$, o que pode acarretar em diversos conflitos, a área central passa a ser mercadoria da cidade para o consumo do turismo cultural. Nesse sentido Paes-Luchiari (2006, p. 8175) afirma que:

\begin{abstract}
Estas novas territorialidades urbanas centrais, ao se apropriarem das formas que encerram longos processos de representação social, provocam rupturas na identidade coletiva local e subvertem o caráter público desses bens históricos. Como exemplo podemos citar os projetos de revitalização dos centros históricos de muitas capitais, sobretudo do Nordeste brasileiro, onde as populações locais mais pobres foram desapropriadas de suas antigas territorialidades para dar lugar a centros culturais, restaurantes, bares, cafés, shoppings, hotéis, casas de espetáculos, lojas de souvenirs, ateliês, acessíveis apenas às populações de alto poder aquisitivo.
\end{abstract}

Todas estas formas de mercantilização dos centros históricos, ditos como espaços de consumo de patrimônio cultural, de alguma maneira são alvo de conflitos entre eventos, serviços e os moradores locais. A questão do conflito entre valor de uso e valor de troca remete a esses espaços a apropriação e a dominação, admitindo então, a utilização da categoria território para realizar a compreensão das relações de poder, e as múltiplas territorialidades, nos quais um território:

[...] em qualquer acepção, tem a ver com poder, mas não apenas ao tradicional "poder político". Ele diz respeito tanto ao poder no sentido mais concreto, de dominação, quanto ao poder no sentido mais simbólico, de

\footnotetext{
5 Ver discussão proposta por Sant Clair Trindade Junior no texto "Patrimônios, Vivências e Representações do Espaço em Políticas de Requalificação Urbana na Amazônia" de 2013. Neste texto o autor discute, a partir da experiência de Belém (Pará), o processo de intervenção urbana onde elementos da cultura, da história e das representações espaciais possuem papel importante em experiências de requalificação urbana.

${ }^{6}$ Planejamento estratégico consiste num modelo que submete as cidades às mesmas condições de uma empresa, articulado com as agências multilaterais, e consultores internacionais, pregam a questão do marketing urbano, em uma produção agressiva de competição entre as cidades (SOUZA, 2008).
} 
apropriação. Lefebvre distingue apropriação de dominação ("possessão", "propriedade"), o primeiro sendo um processo muito mais simbólico, carregado das marcas do "vivido", do valor de uso, o segundo mais concreto, funcional e vinculado ao valor de troca. (HAESBAERT, 2003, p. 6774).

Assim pode-se discutir a respeito das apropriações do patrimônio cultural, uma vez que as intervenções urbanas não se dão de forma homogênea, abrangendo basicamente áreas de maior atratividade turística, paisagens, que possam ser rentáveis para os investidores do local e por vezes de interesse global. Ou até mesmo "mudam-se as funções dos lugares para transformá-los em espaços museológicos, muitas vezes investindo-se recursos públicos vultosos e retirando, além da função, a vida cidadã existente nesses espaços" (MENESES, 2012, p. 32).

Nessa via a respeito da apropriação segundo os preceitos do mercado (valor de troca), Costa (2015) faz um estudo em duas cidades históricas de Mina Gerais (Diamantina e Ouro Preto) e trata da Patrimonialização global a definindo como um processo que ressignifica os lugares da cultura e da natureza em escala planetária, pressupondo a cenarização, espetacularização dos lugares promovidos pelo Estado no âmbito do capital com intuito de tornar os espaços mais competitivos e rentáveis (MORAES; GÂNDARA, 2016).

Assim, discutem-se as estratégias de marketing urbano onde desencadeiam as "novas" cidades na geopolítica da rede global do turismo (COSTA, 2015). Esse novo ordenamento territorial que intencione obedecer às primazias do consumo global do patrimônio, sendo sustentado pela perspectiva de Patrimônio Cultural da Humanidade pela Organização das Nações Unidas para a Educação, a Ciência e a Cultura (UNESCO) - estudado por Costa (2015), pode reconfigurar as funcionalidades no território contribuindo para os jogos de poder na teia territorial, no sentido de desterritorialização e de surgimentos de novas territorialidades.

A discussão entre Patrimônio cultural, cidade e ordenamento territorial contribui no sentido de compreender os mais diversos usos de um determinado espaço de consumo do patrimônio cultural, as novas funções estabelecidas nas formas pretéritas consideradas patrimônio da cidade, as apropriações nas rugosidades espaciais, e as mudanças no espaço geográfico, tanto em sua morfologia, quanto do ponto de vista das funções e dos processos (SANTOS, 2009). 


\section{CONCLUSÃO}

Considera-se poder afirmar que a categoria patrimônio não possui uma base teórica acabada. Sua discussão estará em construção contínua à medida que se trata de um conceito representativo para cada grupo/sociedade. Seus desmembramentos subsidiam novas discussões, por vezes para tornarem-se mais didáticas, tratando da memória coletiva, identidade e representações materiais de culturas da sociedade.

O que se considerar como patrimônio, o que patrimonializar são algumas das principais discussões nesse âmbito. As funções da patrimonialização e as escolhas estão estritamente envolvidas em fatos sociais e bojos políticos e econômicos. Se em primeira instância, no Brasil, se tem a questão do patrimônio subsidiando a construção de um Estado Nacional, uma pátria nacionalista ancorada nos preceitos do estado, atualmente quem dita às regras, em grande medida, são as primazias do mercado, onde as cidades que possuem um aparato simbólico considerado patrimônio tendem a tornar-se cada vez mais valorizadas e rentáveis no âmbito do mercado turístico. Onde o ordenamento territorial, promovido muitas vezes pelo Estado, acaba configurando os espaços patrimoniais para o uso turístico, onde a coexistência de antigas territorialidades e novas territorialidades engendram um campo delicado e conflituoso nas relações socioespaciais.

A discussão sobre apropriação do território a partir do viés do Patrimônio Cultural para o uso turístico subsidia um novo entendimento do espaço urbano, das novas funcionalidades de rugosidades espaciais, e até mesmo de uma proposta para pensar a ideia de cidade antiga no âmbito de uma "nova globalização". Priorizar a vida cotidiana, pela luta por seu território, sua territorialidade e sua reprodução simbólica é proporcionar novas perspectivas para uma cidade mais democrática e humana. Romper com a espetacularização é permitir a reprodução social no espaço para além do segmento de primazias propostas por grupos hegemônicos.

Tentar romper com todas essas premissas pressupõe um minucioso estudo de cada caso sempre imbricado na dialética, pois novas formas de pensar a categoria cidade para além das verticalizações tentando amenizar ao máximo as contradições do espaço, ou pelo menos, dando autonomia nas escolhas para uma cidade a quem a produz cotidianamente em suas relações sociais. 


\section{REFERÊNCIAS}

BERNHARDT, E. M. B. Gentrificação e Revitalização: perspectivas teóricas e seus papéis na construção de espaços urbanos contemporâneos. Revista Urbanidades, Brasília, n. 5, p. 1-22, 2005.

BERTONCELLO, R. Turismo y patrimonio, entre la cultura y el negocio. In: PAES, M. T.; OLIVEIRA, M. (Org.). Geografia, turismo e patrimônio cultural. São Paulo: Annablume, 2010. p. 33-53.

CIFELLI, G. A refuncionalização turística do patrimônio cultural: os novos usos do território apropriado pelo turismo em Ouro Preto-MG. In: PAES, M. T.; OLIVEIRA, M. (Org.). Geografia, turismo e patrimônio cultural. São Paulo: Annablume, p. 115$138,2010$.

CHOAY, F. A alegoria do patrimônio. São Paulo: Editora UNESP, 2001.

COSTA, E. B. Cidades da Patrimonialização Global: Simultaneidade totalidade urbana - totalidade-mundo. São Paulo: Humanitas/Fapesp, 2015.

CRUZ, R. de C. A. da. "Patrimonialização do Patrimônio": ensaio sobre a relação entre turismo, "patrimônio cultural" e produção do espaço. GEOUSP: espaço e tempo, São Paulo, v. 1, n. 31, p. 95-104, 2012.

FIGUEREDO, L. C. Perspectivas de análise geográfica do patrimônio cultural: algumas reflexões. Geografia Ensino \& Pesquisa, v. 17, n. 1, jan./abr. 2013

FOnSECA, M. C. L. O Patrimônio em Processo: trajetória da política federal de preservação no Brasil. 3. ed. Rio de Janeiro: Editora UFRJ, 2009.

GONÇALVES, J. R. S. Ressonância, materialidade e subjetividade: as culturas como patrimônio. Horizontes Antropológicos, Porto Alegre, Ano 11, n. 23, p. 15-36, 2005.

HAESBAERT, R. Da Desterritorialização à Multiterritorialidade. Boletim Gaúcho de Geografia, Porto Alegre, v. 29, n. 1, p. 11-24, 2003.

JEUDY, H. P. Espelho das cidades. Rio de Janeiro: Casa da Palavra, 2005.

MENESES, C. N. J. A Patrimonialização da vida: vivências, memória social e interpretação do patrimônio cultural. In: COSTA, B. E.; BRUSADIN, B. L.; PIRES, C. M. (orgs.). Valor Patrimonial e turismo: limiar entre história, território e poder. 1. ed. São Paulo: Outras Expressões, 2012. p. 23-35.

MORAES, L. A. de; GÂNDARA, J. M. G. Midiatização e espetacularização do turismo. Turismo e Sociedade. Curitiba, v. 9, n. 1, p. 1-18, 2016. 
NIGRO, C. Da Defesa do Patrimônio ao Turismo Cultural, X ENCONTRO DE GEÓGRAFOS DA AMÉRICA LATINA, 20 a 26 de Março de 2005, Anais... Universidade de São Paulo.

As dimensões culturais e simbólicas nos estudos geográficos: bases e especificidades da relação entre patrimônio cultural e geografia. In: PAES, M. T.; OLIVEIRA, M. (Org.). Geografia, turismo e patrimônio cultural. São Paulo: Annablume, 2010. p. 55-80.

PAES, M. T. D. Patrimônio cultural, turismo e identidades territoriais um olhar geográfico. In: BARTHOLO, R.; BURSZTYN, I.; SANSOLO, D. (Org.). Turismo de Base Comunitária: diversidade de olhares e experiências brasileiras. Rio de Janeiro: Letra e Imagem, 2009. p. 162-176.

PAES-LUCHIARI, M. T. D. Centros históricos - mercantilização e territorialidades do patrimônio cultural urbano, Geographia, Ano 7, n. 14, p. 43-57. 2006

SANTOS, M. A Natureza do Espaço - técnica e tempo. Razão e emoção. 4. ed. São Paulo: Editora da Universidade de São Paulo, 2009.

SERRANO, C. Patrimônio, natureza e cultura: uma introdução a olhares e práticas. In: PAES-LUCHIARI, M. T. D.; BRUHNS, H. T.; SERRANO, C. (Orgs.). Patrimônio, natureza e Cultura. 1. ed. Campinas, SP: Papirus, 2007, p. 9-25.

SCIFONI, S. Por uma geografia política dos patrimônios naturais. In: PAES, M. T.; OLIVEIRA, M. (Org.). Geografia, turismo e patrimônio cultural. São Paulo: Annablume, 2010. p. 207-226.

SOUZA, M. L. Mudar a cidade: Uma crítica ao planejamento e à gestão urbanos. Rio de Janeiro: Bertrand Brasil, 2008.

TRINDADE JR., S-C. C. De volta ao rio: estratégias de gestão e de (re)apropriação do espaço urbano na área central de Belém. In: TRINDADE JR., S-C. C.; TAVARES, M. G. C. (Org.). Cidades ribeirinhas na Amazônia: mudanças e permanências. 1. ed. Belém: EDUFPA, 2008, v. 1, p. 145-156.

Recebido em: 16-08-2017.

Aprovado em: 15-09-2017. 